\title{
Detection of eight foodborne bacterial pathogens by oligonucleotide array hybridization
}

\author{
Zohreh Nasrabadi ${ }^{1}$, Reza Ranjbar ${ }^{2}$, Fatemeh Poorali ${ }^{2}$, Meysam Sarshar ${ }^{3}$
}

${ }^{1}$ Department of Microbiology, Faculty of Science, Islamic Azad University, Karaj branch, Karaj, Iran

${ }^{2}$ Molecular Biology Research Center, Baqiyatallah University of Medical Sciences, Tehran, Iran

${ }^{3}$ Department of Public Health and Infectious Diseases, Sapienza University of Rome, Laboratory affiliated to

Institute Pasteur Italia-Fondazione Cenci Bolognetti, Rome, Italy

\section{Type of article: Original}

\begin{abstract}
Background: Simultaneous and rapid detection of multiple foodborne bacterial pathogens is important for the prevention of foodborne illnesses.

Objective: The aim of this study was to evaluate the use of $16 S \mathrm{rDNA}$ and $23 \mathrm{~S} r D N A$ sequences as targets for simultaneous detection of eight foodborne bacterial pathogens.

Methods: Nineteen bacterial oligonucleotide probes were synthesized and applied to nylon membranes. Digoxygenin labeled $16 \mathrm{~S} r D N A$ and $23 \mathrm{~S} r D N A$ from bacteria were amplified by PCR using universal primers, and the amplicons were hybridized to the membrane array. Hybridization signals were visualized by NBT/BCIP color development.

Results: The eight intestinal bacterial pathogens including Salmonella enterica, Escherichia coli, Bacillus cereus, Vibrio cholerae, Shigella dysenteriae, Staphylococcus aureus, Listeria monocytogenes, and Enterococcus faecalis were appropriately detected in a panel of oligonucleotide array hybridization. The experimental results showed that the method could discriminate the bacterial pathogens successfully. The sensitivity of oligonucleotide array was $10^{3} \mathrm{CFU} / \mathrm{ml}$.

Conclusion: This study showed that $16 S r D N A$ and $23 S r D N A$ genes had sufficient sequence diversity for species identification and were useful for monitoring the populations of foodborne pathogenic bacteria. Furthermore, results obtained in this study revealed that oligonucleotide array hybridization had a powerful capability to detect and identify the bacterial pathogens simultaneously.
\end{abstract}

Keywords: Oligonucleotide array, foodborne pathogens, $16 \mathrm{~S} r D N A$ and $23 \mathrm{~S} r D N A$, Hybridization

\section{Introduction}

Foodborne pathogenic microorganisms are responsible for significant health problems and sometimes lifethreatening for millions of people throughout the world. Several agents such as bacteria, parasites, fungi and chemical toxins are responsible for food-borne diseases (1-4). Escherichia coli, Shigella spp, Salmonella spp, Bacillus cereus, Listeria monocytogenes, Enterococcus faecalis, Staphylococcus aureus and Vibrio cholera are amongst the most important food-borne bacterial pathogens (4-7). The infections caused by these bacterial pathogens are endemic now in many countries and cause a wide range of morbidity and mortality $(6,8-13)$. Routine detection of bacterial pathogens in clinical laboratories is based on enrichment culture, microscopic observation and biochemical assay (14-17). Although culture testing is the gold standard for the assessment of infectious diseases, the whole procedure has several limitations, such as being time-consuming, laborious, and the difficulty of quantitative analysis. Furthermore, these methods are not capable of detecting several pathogens simultaneously, so there is a need for the rapid identification of food-borne bacterial pathogens using methods with high sensitivity (1518). In order to overcome such limitations, the development of molecular-based methods such as polymerase chain

\section{Corresponding author:}

Professor Dr. Reza Ranjbar, Molecular Biology Research Center, Baqiyatallah University of Medical Sciences, Tehran, Iran. Telephone: +98.2188039883, Fax: 98.2188039883, Email: ranjbarre@gmail.com

Received: March 16, 2016, Accepted: February 10, 2017, Published: May 2017

iThenticate screening: September 21, 2016, English editing: April 12, 2017, Quality control: April 28, 2017

(C) 2017 The Authors. This is an open access article under the terms of the Creative Commons Attribution-NonCommercialNoDerivs License, which permits use and distribution in any medium, provided the original work is properly cited, the use is non-commercial and no modifications or adaptations are made. 
reaction (PCR) and immunoassay were introduced. Although PCR is one of the most important molecular techniques, because of having potential for detecting microorganisms, this method is also very time-consuming and is not suitable for screening. Most PCR methods are not able to immediately differentiate different bacterial species. For that reason, there is a significant need for an advanced diagnostic system which would be capable of identifying large amounts of intestinal pathogens simultaneously. Molecular techniques for the detection of food-borne pathogens are being developed to improve characteristics such as sensitivity, selectivity, rapidity, reliability, effectiveness and suitability for in situ analysis $(19,20)$. Array technology is a very effective means of simultaneously detecting thousands of genes or target DNA sequences on a single nylon membrane $(21,22)$. Nowadays, it has been broadly accepted that $r D N A$ genes are the potential tools for the identification of enteric bacteria $(21,23-25)$. In the present study, information from $16 S$ rDNA and $23 S$ rDNA were used as the detection principles, considering these sequences exist universally in bacteria, and thus present general and specific information for identification of organisms. Numerous DNA chip-based pathogen detection systems have been documented as employing this sequence. The sequences of the $16 S \mathrm{rDNA}$ and $23 \mathrm{~S} r D N A$ regions exhibits greater variations than that of the $16 \mathrm{~S} r D N A$ structural gene and hence it is more suitable for designing specific primers or probes to identify closely related bacterial species. The aim of this study was to evaluate the use of $16 \mathrm{~S} r D N A$ and 23S rDNA genes for simultaneous detection of eight foodborne bacterial pathogens.

\section{Material and Methods}

\subsection{Bacterial Strains and culture condition}

The study was carried out in the laboratory of Molecular Biology Research Center, Baqiyatallah University of Medical Sciences (Tehran, Iran) during 2012-13. Eight common bacterial species that cause food-borne infections were selected in our study. They were Salmonella enterica, Escherichia coli, Bacillus cereus, Vibrio cholerae, Shigella dysenteriae, Staphylococcus aureus, Listeria monocytogenes, Enterococcus faecalis. The referenced bacterial strains used in this study were provided from the Centers for Microbiological Culture Collection (CMCC), Pasteur Institute of Iran in 2011, and were identified and confirmed by a combination of conventional serology methods. The referenced bacterial strains were cultured on LB Agar and BHI Agar based on conventional methods and then stored in an incubator for 17-20 hours. Pure cultures of two or three species of these bacteria were mixed and diluted as food-borne test organism mixtures. Each species of bacterium was diluted from 1 to $10^{6} \mathrm{CFU} / \mathrm{ml}$. Test organism mixture 1 contained bacterial species of $S$. aureus, E. coli, E. faecalis and L. monocytogenes, test organism mixture 2 contained bacterial species of $S$. enterica, $V$. cholera, Sh. dysenteriae, and test organism mixture 3 contained bacterial species of $B$. cereus and E. coli.

\subsection{DNA Isolation and PCR Amplification}

A single colony was diluted in $100 \mu \mathrm{l}$ of distilled water in Eppendorf tubes. First a single colony of the bacteria was cultured in $5 \mathrm{ml}$ of LB broth overnight, then, $200 \mu \mathrm{l}$ of the culture was added to Eppendorf tubes. DNA of the bacteria was extracted using the Genomic DNA Purification Kit (Fermentas, Lithuania). The amplification conditions of tubes were one cycle of $94^{\circ} \mathrm{C}$ for 4 min, then 35 cycles of consisting of denaturation $\left(94{ }^{\circ} \mathrm{C}\right.$ for $\left.45 \mathrm{~s}\right)$, annealing $\left(60{ }^{\circ} \mathrm{C}\right.$ for $\left.45 \mathrm{~s}\right)$, and extension $\left(72^{\circ} \mathrm{C}\right.$ for $\left.45 \mathrm{~s}\right)$, with a final extension step at $72{ }^{\circ} \mathrm{C}$ for $7 \mathrm{~min}$.

\subsection{Design oligonucleotide probes and PCR primers}

Alignment of $16 \mathrm{~S} r D N A$ and $23 \mathrm{~S} r D N A$ sequences of 8 species of food-borne pathogenic bacteria were performed by the Clustal W algorithm with Align X (a component of Vector NTI Advance 11.0). The selected variable regions of the alignment were checked for self-binding, GC content, secondary structure, and melting temperature (Tm) by the Vector NTI (Invitrogen Corporation, Carlsbad, CA, USA) software and screened for homology with other bacterial sequences using the National Center for Biotechnology BLAST (Basic Local Alignment Search Tool). Oligonucleotide probes were selected from the variable regions of different species for each bacterium (total of 19 robes) and synthesized to make microarray by the custom service of the company. The nineteen oligonucleotide probes are listed in Table 1. The universal primers (corresponding to 1051-1957 nucleotide sequence of $r D N A$ genes based on conserved regions of bacterial $16 \mathrm{~S} r D N A$ and $23 \mathrm{~S} r D N A$ sequences were designed (26). They were as follows:

16SF: (5'CGCTGGCGGCAGGCCTAACACATGCGCGGCTGCTGGCACGGAGTTAGCC3') 16SR: (5'CAGCCACACTGGAACTGAGACACGTCCTGTTTGCTCCCCACGCTTTCG3'); 23SF: (5'ACCGATAGTGAACCAGTACCGTGAGACCGATAGTGAACCAGTACCGTGAG3') and 23SR: (5'AGGATGTTGGCTTAGAAGCAGCGCTACCTTAGGACCGTTATAGTTAC 3'). The forward primers of both $16 S r D N A$ and $23 S r D N A$ genes were labeled with a digoxigenin dye (Metabion, Germany). 
Table 1. Oligonucleotide probes used in this study

\begin{tabular}{|c|c|c|}
\hline No. & Bacterial name & Probe sequences (5' to 3 ') \\
\hline 1 & 16S E. coli & GGGAGGAAGGGAGTAAAGTTAATACCTTTGCTCATTGACG \\
\hline 2 & 23S E. coli & GATATGTAGGTGAAGCGACTTGCTCGTGGAGCTGAAATC \\
\hline 3 & 16S Sh. dysenteriae & CGGTAACAGAAAGCAGCTTGCTGCTTTGCTGACGAGT \\
\hline 4 & 23S Sh. dysenteriae & GATATGTAGGTGAAGTCCCTCGCGGATGGAGCTGAAATC \\
\hline 5 & 16S S. typhimurium & TTTACTCTCTAAGGACAAGTTGTGACGGGGAGCGAAATAATAGTAGC \\
\hline 6 & 23S S. typhimurium & TGTGTGTTCCAGGTAAATCCGGTTCACTTTAACACTGAGGC \\
\hline 7 & 16S V. cholerae & TAGGGAGGAAGGTGGTTAAGTTAATACCTTAATCATTTGACGTTACCTA \\
\hline 8 & 23S V. cholerae & TCTGTAAGCCGTTGAAGGTGAATCGTAAGGTTTGCTGGAGGTATC \\
\hline 9 & 16S B. cereus & TGTTAGGGAAGAACAAGTGCTAGTTGAATAAGCTGGCACCTTGA \\
\hline 10 & 23S B. cereus & GGTGCTTTCTTAACGGAAAGCCGCAGTGAATAGGCCCAAGCG \\
\hline 11 & 16S E. faecalis & CTTCTTTCCTCCCGAGTGCTTGCACTCAATTGGAAAGAGGAGT \\
\hline 12 & 23S E. faecalis & CCGATGCAAACTGCGAATACCGGAGAATGTTATCACG \\
\hline 13 & 16S L. monocytogenes & ACGAACGGAGGAAGAGCTTGCTCTTCCAATGTTAGTGGCG \\
\hline 14 & 23S L. monocytogenes & GGAATCGCACGAATGGAAATGTGCGTCCAAGCAGTGAGTGTGAGAAGT \\
\hline 15 & 16S S. aureus & TATTAGGGAAGAACATATGTGTAAGTAACTGTGCACATCTTGA \\
\hline 16 & 23S S. aureus & GGGAGAAGACATTGAGTCTTCGAGTCGTTGATTTCACACTGCCGAG \\
\hline 17 & Universal probe & CACACTGGAACTGAGACACGGTCGAGACTCCTACGGGA \\
\hline 18 & $\begin{array}{l}\text { Enterobacteriaceae } \\
\text { probe }\end{array}$ & TATTAGGGAAGAACATATGTGTAAGTAACTGTGCACATCTTGA \\
\hline 19 & $\begin{array}{l}\text { Aequorea victoria } \\
\text { GFP* (positive } \\
\text { control) }\end{array}$ & CAGAGTGTGCGATATTGATGAAAGTG \\
\hline
\end{tabular}

${ }^{*}$ Green Fluorescent Protein.

\subsection{Oligonucleotide array preparation}

Probes were prepared at a concentration of $20 \mu \mathrm{mol} / \mathrm{L}$. Probe solution was spotted on the nylon membrane (Fermentas, Lithuania) with an amount of 1 microliter in specific position. With the addition of a positive control DNA amplicon to the hybridization buffer, the two controls were capable of providing verification of the amplification and hybridization process within the developed assay. The probes were fixed and cross linked by UV crosslinker for 30 seconds to allow binding of probes onto the nylon membrane. When the oligonucleotides had been cross linked to the membrane, all unbound oligonucleotides were eradicated by two washes using [0.5x SSC (1x SSC is $0.15 \mathrm{M} \mathrm{NaCl}$ plus $0.015 \mathrm{M}$ sodium citrate), $0.1 \%$ sodium dodecyl sulfate (SDS)] for two minutes at 37 ${ }^{\circ} \mathrm{C}$. Then the strips were dried and stored at room temperature, for later use.

The layout of the probes is shown in Table 2.

Table 2. Layout of oligonucleotide probes

\begin{tabular}{|l|l|l|l|l|}
\hline Universal & 1 & 2 & 3 & Positive Control \\
\hline 4 & 5 & 6 & 7 & 8 \\
\hline 9 & 10 & 11 & 12 & 13 \\
\hline 14 & 15 & 16 & Positive Control & 18 \\
\hline
\end{tabular}

\subsection{Hybridization and Signal detection}

Hybridization was performed for two hours with $1 \mathrm{ml}$ of hybridization solution 5X SSC, $1 \%$ [wt/vol] blocking reagent, $0.1 \%$ N-laurylsarcosine, $0.02 \%$ SDS. Ten microliters of the labeled PCR product were diluted with $0.5 \mathrm{ml}$ of hybridization solution and added to each well. The reaction was done at $50{ }^{\circ} \mathrm{C}$ for $90 \mathrm{~min}$. The membrane was washed in one $\mathrm{ml}$ of washing buffer 1 (1 minute) then in one $\mathrm{ml}$ of a second washing buffer 2 . The array was then blocked with $1 \%$ blocking solution. Approximately $0.5 \mathrm{ml}$ of alkaline phosphatase conjugated sheep antidigoxigenin antibodies (diluted 1:5000 in blocking solution) was added to each and the plate was incubated at $37^{\circ} \mathrm{C}$ for 1 hour (without shaking). NBT/BCIP color development was clearly visible between 30 minutes and one hour after the start of the reaction $(26,27)$.

\section{Results}

\subsection{Amplification of $16 S \mathrm{rDNA}$ and $23 \mathrm{~S}$ rDNA primers}

PCR amplification of the eight bacterial strains showed the $500 \mathrm{bp}$ size for $16 S \mathrm{rDNA}$ gene and $880 \mathrm{bp}$ size for the 23S rDNA gene. The quality control of PCR products showed that all of them have been labeled with Digoxygenin (DIG). 


\subsection{Array of oligonucleotide probes}

Amplified $16 S$ rDNA and $23 S$ rDNAs from the eight bacteria species were successfully hybridized with oligonucleotide probes that were attached on nylon membranes. Results of the oligonucleotide array hybridization for the eight bacterial species can be seen in Figure 1. The nineteen oligonucleotide probes were arrayed in suitable grids on the nylon membrane in order to facilitate the hybridization result analysis of the various bacterial species. We designed two or three probes for some species to ensure the sensitivity and specificity.

\subsection{Pure bacterial culture and mock sample hybridization results}

High sensitivity and specificity were obtained when the method was evaluated with other species of bacteria, including S. enterica, E. coli, B. cereus, $V$. cholerae, Sh. dysenteriae, S. aureus, L. monocytogenes, and E. faecalis (Figure 1). PCR products from each bacterial sample were hybridized with oligonucleotide probes attached to nylon membranes. The results showed high specificity of hybridization with bacterial species under investigation. With the exception of Sh. dysenteriae and E. coli strains (more than $90 \%$ similarity in $16 S$ rDNA gene), in other bacteria, each probe hybridized by only one genus of bacteria or all of the species of that genus. Positive hybridization was found with bacterial mixture no.1 (S. aureus, E. coli, E. faecalis and L. monocytogenes), no.2 (S. enterica, V. cholera and Sh. dysenteriae), and no.3 (B. cereus and E. coli) (Figure 2).

\subsection{Sensitivity of dot blot Hybridization technique}

Sensitivity of the PCR assay was randomly performed to test the lower detection limit of the DNA microarrays. At first, each species of bacterium of mock samples was diluted from 1 to $10^{6} \mathrm{CFU} / \mathrm{ml}$. Then, each dilution was extracted and amplified by PCR reaction. Finally, all were mixed and tested by dot blot hybridization. Positive signals could be obtained from dilutions between $10^{3}$ and $10^{9} \mathrm{CFU} / \mathrm{ml}$. If the titer of dilutions was below 10 $\mathrm{CFU} / \mathrm{ml}$, the results were considered as negative. The results showed that the sensitivity of oligonucleotide array was $10^{3} \mathrm{CFU} / \mathrm{ml}$.
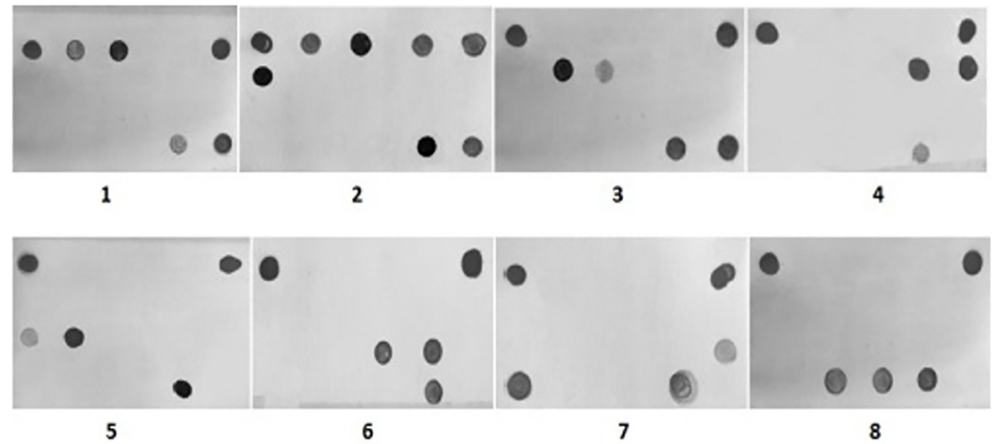

Figure 1. Oligonucleotide hybridization results of selected bacteria: 1. E. coli, 2. Sh. dysenteriae, 3. S. enterica, 4. B. cereus, 5. L. monocytogenes, 6. E. faecalis, 7. S. aureus, 8. V. cholera

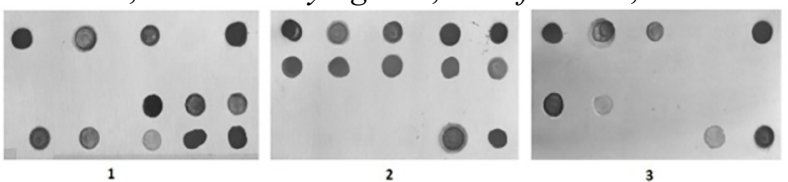

Figure 2. Simultaneous detection results of oligonucleotide hybridization in 3 groups of bacteria. 1. These groups consist of E. faecalis, L. monocytogenes, S. aureus and E. coli; 2. V. cholerae, S. enterica and Sh. dysenteriae; 3. B. cereus and E. coli.

\section{Discussion}

DNA microarray technology, consisting of the hybridization of nucleic acid fragments (either from chemical or enzymatic synthesis) immobilized onto a solid surface with the nucleic acid of a test sample, was first reported at the end of the 1990s (21-23). It is a rapid and sensitive method to detect and identify the intestinal pathogens simultaneously, and facilitate the investigation of biological reactions. Probe characteristics are an important issue to reach the success in dot-blot method (22-25). Our probes were prepared based on comparison of the $16 S \mathrm{rDNA}$ and $23 S$ rDNA genes sequences of eight intestinal pathogenic species to locate variable regions containing signature sequences for eight intestinal pathogens: E. coli, Sh. dysenteriae, S. enterica, B. cereus, L. monocytogenes, E. faecalis, $S$. aureus, and $V$. cholera. Degree of sequence mismatching is important to obtain target specificity (28, 29). Microarrays can be combined with other methods to augment the detection and identification of products (30, 
31). Tissari et al., in cases of positive cultures, compared the use of PCR followed by a DNA microarray with blood cultures, and found the PCR-DNA microarray approach to have acceptable sensitivity, specificity, and rapidity, however, the DNA microarray continues to be a less common approach to microbial diagnostics $(32,33)$. Processing of microarrays is another significant aspect in the effective detection of hybridization signals. Processing methods suggested by the manufacturer were initially used to hybridize procedures. However, no signals or nonspecific signals were obtained. In this study, modifications were made in time and temperature of incubation of solution in shaker incubator, which allowed us to obtain clear, strong hybridization signals.

Nowadays, the rDNA genes have been generally accepted as the potential tools for the identification and phylogenetic analysis of bacteria (34). The $r D N A$ genes are in each bacterial cell. They have a size of about 1500 3000 nucleotides for $16 S r D N A$ and $23 S r D N A$ genes and, also, protectable and variable regions in these genes (35). The $16 S$ rDNA or $23 S$ rDNA targeted hybridization probes and polymerase chain reaction (PCR) primers have been applied successfully to the identification and detection of bacteria species (36). However, in the case of closely related species (Shigella spp, Salmonella spp, and E. coli), $16 \mathrm{~S} r D N A$ probes or primers have not been used due to little variation of the $16 \mathrm{~S} r D N A$ sequence, and these three genera can hardly be identified by only this gene (37). Therefore, the 23S rDNA sequence was chosen as the target because earlier studies had shown that in comparison to that of the corresponding $16 \mathrm{SrDNA}$ sequence, it had a higher degree of inconsistency, particularly in the region used in this study $(38,39)$. Applying of both $16 S \mathrm{rDNA}$ and $23 \mathrm{~S} r D N A$ genes in the same panel of hybridization, display greater variations respect to utilizing only $16 r D N A$ structural gene and is therefore more appropriate in designing specific primers or probes when identifying closely related species (40). Using this technique, complex mixtures of bacteria were more easily distinguishable. The final results were attained within five hours, and the time could even be considerably reduced following further improvements to the DNA extraction and hybridization procedure.

\section{Conclusions}

The $16 S r D N A$ and $23 S r D N A$ genes showed sufficient sequence diversity for species identification and monitoring the populations of foodborne pathogenic bacteria. Also, oligonucleotide array hybridization had a powerful capability to detect and identify the bacterial pathogens simultaneously. It is suggested to use the oligonucleotide array technique for determination of other microorganisms, such as viruses and parasites. Performing a supplementary research about variable and conserved regions of ribosomal genes for the selection of better regions in order to design primers and probes can be an appropriate point for further research.

\section{Acknowledgments:}

This work was financially supported by the Molecular Biology Research Center, Baqiyatallah University of Medical Sciences, Tehran, Iran, Deputy of Research and Technology, Ministry of Health and Medical education, Tehran, Iran with an international collaboration with the Department of Sciences for Health Promotion and Mother-Child Care, G. D'Alessandro, University of Palermo, Palermo, Italy.

\section{Conflict of Interest:}

There is no conflict of interest to be declared.

Authors' contributions:

All authors contributed to this project and article equally. All authors read and approved the final manuscript.

\section{References:}

1) Masoumi Asl H, Gouya MM, Soltan-Dallal MM, Aghili N. Surveillance for foodborne disease outbreaks in Iran, 2006-2011. Med J Islam Repub Iran. 2015; 29: 285. PMID: 26913248, PMCID: PMC4764277.

2) Ranjbar R, Mammina C, Pourshafie MR, Soltan-Dallal MM. Characterization of endemic Shigella boydii strains isolated in Iran by serotyping, antimicrobial resistance, plasmid profile, ribotyping and pulsed-field gel electrophoresis. BMC Res Notes. 2008; 1: 74. doi: 10.1186/1756-0500-1-74. PMID: 18755045, PMCID: PMC2547104.

3) Filliol-Toutain I, Chiou CS, Mammina C, Gerner-Smidt P, Thong KL, Phung DC, et al. Global distribution of Shigella sonnei clones. Emerg Infect Dis. 2011; 17(10): 1910-2. doi: 10.3201/eid1710.101486. PMID: 22000369, PMCID: PMC3310650.

4) Kirk MD, Pires SM, Black RE, Caipo M, Crump JA, Devleesschauwer B, et al. World Health Organization Estimates of the Global and Regional Disease Burden of 22 Foodborne Bacterial, Protozoal, and Viral 
Diseases, 2010: A Data Synthesis. PLoS Med. 2015; 12(12): e1001921. doi: 10.1371/journal.pmed.1001921. PMID: 26633831, PMCID: PMC4668831.

5) Yang X, Noyes NR, Doster E, Martin JN, Linke LM, Magnuson RJ, et al. Use of Metagenomic Shotgun Sequencing Technology To Detect Foodborne Pathogens within the Microbiome of the Beef Production Chain. Appl Environ Microbiol. 2016; 82(8): 2433-43. doi: 10.1128/AEM.00078-16. PMID: 26873315, PMCID: PMC4959480.

6) Ranjbar R, Hosseini MJ, Kaffashian AR, Farshad S. An outbreak of shigellosis due to Shigella flexneri serotype 3a in a prison in Iran. Arch Iran Med. 2010; 13(5): 413-6. doi: 010135/AIM.008. PMID: 20804308.

7) Ranjbar R, Behnood V, Memariani H, Najafi A, Moghbeli M, Mammina C. Molecular characterisation of quinolone-resistant Shigella strains isolated in Tehran, Iran. J Glob Antimicrob Resist. 2016; 5: 26-30. doi: 10.1016/j.jgar.2016.01.010. PMID: 27436462.

8) Ranjbar R, Rahbar M, Naghoni A, Farshad S, Davari A, Shahcheraghi F. A cholera outbreak associated with drinking contaminated well water. Arch Iran Med. 2011; 14(5): 339-40. PMID: 21888459.

9) Momtaz H, Karimian A, Madani M, Safarpoor Dehkordi F, Ranjbar R, Sarshar M, et al. Uropathogenic Escherichia coli in Iran: serogroup distributions, virulence factors and antimicrobial resistance properties. Ann Clin Microbiol Antimicrob. 2013; 12: 8. doi: 10.1186/1476-0711-12-8. PMID: 23627669, PMCID: PMC3651382.

10) Pourshafie MR, Bakhshi B, Ranjbar R, Sedaghat M, Sadeghifard N, Zaemi Yazdi J, et al. Dissemination of a single Vibrio cholerae clone in cholera outbreaks during 2005 in Iran. J Med Microbiol. 2007; 56(Pt 12): 1615-9. doi: 10.1099/jmm.0.47218-0. PMID: 18033829.

11) Ranjbar R, Soltan Dallal MM, Talebi M, Pourshafie MR. Increased isolation and characterization of Shigella sonnei obtained from hospitalized children in Tehran, Iran. J Health Popul Nutr. 2008; 26(4): 42630. PMID: 19069621, PMCID: PMC2740698.

12) Ardakani MA, Ranjbar R. Molecular typing of uropathogenic E. coli strains by ERIC-PCR method. Electron Physician. 2016 25; 8(4):2291-6. doi: 10.19082/2291. PMID: 27280007, PMCID: PMC4886573.

13) Anvarinejad M, Farshad Sh, Ranjbar R, Giammanco GM, Alborzi A, Japoni A. Genotypic Analysis of E. coli Strains Isolated from Patients with Cystitis and Pyelonephritis. Iran Red Crescent Med J. 2012; 14(7): 408-16. PMID: 22997556, PMCID: PMC3438433.

14) Mao Z, Zheng H, Wang $X$, Lin S, Sun $Y$, Jiang B. DNA microarray for direct identification of bacterial pathogens in human stool samples. Digestion. 2008; 78(2-3): 131-8. doi: 10.1159/000174465. PMID: 19011283.

15) Valencia-Shelton F, Loeffelholz M. Nonculture techniques for the detection of bacteremia and fungemia Frances. Future Microbiol. 2014; 9(4): 543-59. doi: 10.2217/fmb.14.8. PMID: 24810352.

16) Ranjbar R, Karami A, Farshad S, Giammanco GM, Mammina C. Typing methods used in the molecular epidemiology of microbial pathogens: a how-to guide. New Microbiol. 2014; 37(1): 1-15. PMID: 24531166.

17) Park Y, Kim DS, Park SJ, Seo HY, Lee SR, Sung HJ, et al. The suggestion of a risk stratification system for febrile neutropenia in patients with hematologic disease. Leuk Res. 2010; 34(3): 294-300. doi: 10.1016/j.leukres.2009.08.024. PMID: 19762083.

18) Espy MJ, Uhl JR, Sloan LM, Buckwalter SP, Jones MF, Vetter EA. Real-time PCR in clinical microbiology: applications for routine laboratory testing. Clin Microbiol Rev. 2006, 19(1): 165-256. doi: 10.1128/CMR.19.1.165-256.2006. PMID: 16418529, PMCID: PMC1360278.

19) Shang $S$, Chen $Z$, Yu X. Detection of bacterial DNA by PCR and reverse hybrid-ization in the 16S rRNA gene with particular reference to neonatal septicemia. Acta Paediatr. 2001; 90: 179-83. doi: 10.1111/j.1651-2227.2001.tb00281.x. PMID: 11236048.

20) Velusamy V, Arshak K, Korostynska O, Oliwa K, Adley C. An overview of foodborne pathogen detection: In the perspective of biosensors. Biotechnol Adv. 2010, 28(2): 232-54. doi: 10.1016/j.biotechadv.2009.12.004. PMID: 20006978.

21) Frickmann H, Dekker D, Schwarz NG, Hahn A, Boahen K, Sarpong N, et al. 16S rRNA Gene SequenceBased Identification of Bacteria in Automatically Incubated Blood Culture Materials from Tropical SubSaharan Africa. PLoS One. 2015; 10(8): e0135923. doi: 10.1371/journal.pone.0135923. PMID: 26270631, PMCID: PMC4535881.

22) Wu L, Thompson DK, Li G, Hurt RA, Tiedje JM, Zhou J. Development and evaluation of functional gene arrays for detection of selected genes in the environment. Appl Environ Microbial. 2001; 67(12): 5780-90. doi: 10.1128/AEM.67.12.5780-5790.2001. PMID: 11722935, PMCID: PMC93372. 
23) Wang RF, Beggs ML, Erickson BD, Cerniglia CE. DNA microarray analysis of predominant human intestinal bacteria in fecal samples. Mol Cell Probes. 2004; 18: 223-34. doi: 10.1016/j.mcp.2004.03.002. PMID: 15271382.

24) Eoma HS, Hwang BH, Kimb DH, Lee IB, Kimc YH, Chaa HJ. Multiple detection of food-borne pathogenic bacteria using a novel $16 \mathrm{~S}$ rDNA-based oligonucleotide signature chip. Biosens and Bioelectron. 2007; 22(6): 845-53. doi: 10.1016/j.bios.2006.03.005. PMID: 16621503.

25) Govindarajan R, Duraiyan J, Kaliyappan K, Palanisamy M. Microarray and its applications. J Pharm Bioallied Sci. 2012; 4(2): 310-2. doi: 10.4103/0975-7406.100283. PMID: 23066278, PMCID: PMC3467903.

26) Hong BX, Jiang LF, Hu YS, Fang DY, Guo HY. Application of oligonucleotide array technology for the rapid detection of pathogenic bacteria of foodborne infections. J Microbiol Methods. 2004; 58(3): 403-11. doi: 10.1016/j.mimet.2004.05.005. PMID: 15279944.

27) Lee DY, Shannon K, Beaudette LA. Detection of bacterial pathogens in municipal wastewater using an oligonucleotide mi-croarray and real-time quantitative PCR. J Microbiol Methods. 2006; 65(3): $453-67$. doi: 10.1016/j.mimet.2005.09.008. PMID: 16239042.

28) Sarshar M, Shahrokhi N, Ranjbar R, Mammina C. Simultaneous Detection of Escherichia coli, Salmonella enterica, Listeria monocytogenes and Bacillus cereus by Oligonucleotide Microarray. Int J Enteric Pathog. 2015; 3(4): e30187. doi: 10.17795/ijep30187.

29) Yoo SM, Choi JY, Yun JK, Choi JK, Shin SY, Lee K, et al. DNA microarray-based identification of bacterial and fungal pathogens in bloodstream infections. Mol Cell Probes. 2010; 24: 44-52. doi: 10.1016/j.mcp.2009.09.003. PMID: 19818395, PMCID: PMC3889773.

30) Cai HY, Caswell JL, Prescott JF. Nonculture Molecular Techniques for Diagnosis of Bacterial Disease in Animals. A Diagnostic Laboratory Perspective. Vet Pathol. 2014; 51(2): 341-350. doi: 10.1177/0300985813511132. PMID: 24569613.

31) Hang J, Desai V, Zavaljevski N, Yang Y, Lin X, Satya RV, et al. 16S rRNA gene pyrosequencing of reference and clinical samples and investigation of the temperature stability of microbiome profiles. Microbiome. 2014; 2: 31. doi: 10.1186/2049-2618-2-31. PMID: 25228989, PMCID: PMC4165438.

32) Tissari P, Zumla A, Tarkka E, Mero S, Savolainen L, Vaara M, et al. Accurate and rapid identification of bacterial species from positive blood cultures with a DNA-based microarray platform: an observational study. The Lancet. 2010; 375: 224-30. doi: 10.1016/S0140-6736(09)61569-5.

33) Pariset L, Chillemi G, Bongiorni S, Romano Spica V, Valentini A. Microarrays and high-throughput transcriptomic analysis in species with incomplete availability of genomic sequences. N Biotechnol. 2009; 25(5): 272-9. doi: 10.1016/j.nbt.2009.03.013. PMID: 19446516.

34) Schwendimann L, Kauf P, Fieseler L, Gantenbein-Demarchi C, Miescher Schwenninger S. Development of a quantitative PCR assay for rapid detection of Lactobacillus plantarum and Lactobacillus fermentum in cocoa bean fermentation. J Microbiol Methods. 2015; 115: 94-9. doi: 10.1016/j.mimet.2015.05.022. PMID: 26026241.

35) Tsui CK, Woodhall J, Chen W, Lévesque CA, Lau A, Schoen CD, et al. Molecular techniques for pathogen identification and fungus detection in the environment. IMA Fungus. 2011; 2(2): 177-89. doi: 10.5598/imafungus.2011.02.02.09. PMID: 22679603, PMCID: PMC3359816.

36) Gey A, Werckenthin C, Poppert S, Straubinger RK. Identification of pathogens in mastitis milk samples with fluorescent in situ hybridization. J Vet Diagn Invest. 2013; 25(3): 386-94. doi: 10.1128/AEM.0104214. PMID: 23632662.

37) Oguntoyinbo FA, Narbad A. Molecular characterization of lactic acid bacteria and in situ amylase expression during traditional fermentation of cereal foods. Food Microbiol. 2012; 31(2): 254-62. doi: 10.1016/j.fm.2012.03.004. PMID: 22608231.

38) Khademi F, Faghri J, Moghim S, Esfahani BN, Fazeli H, Poursina F, et al. The study of mutation in $23 \mathrm{~S}$ rRNA resistance gene of Helicobacter pylori to clartithromycin in patients with gastrointestinal disorders in Isfahan - Iran. Adv Biomed Res. 2014; 3: 98. doi: 10.4103/2277-9175.129368. PMID: 24800187, PMCID: PMC4007339.

39) Chen IC, Griesenauer B, Yu YT, Velicer GJ. A recent evolutionary origin of a bacterial small RNA that controls multicellular fruiting body development. Mol Phylogenet Evol. 2014; 73: 1-9. doi: 10.1016/j.ympev.2014.01.001. PMID: 24418530.

40) Lin YT, Vaneechoutte M, Huang AH, Teng LJ, Chen HM, Su SL, et al. Identification of Clinically Important Anaerobic Bacteria by an Oligonucleotide Array. J Clin Microbiol. 2010; 48(4): 1283-90. doi: 10.1128/JCM.01620-09. PMID: 20129959, PMCID: PMC2849602. 